\title{
LIDERANÇA: UM ESTUDO SOBRE COMO O "BOM ÂNIMO" FAVORECE A BOA LIDERANÇA
}

\section{ENSAIO TEÓRICO}

GARCIA, Pâmela Ribeiro ${ }^{1}$

GARCIA, Pâmela Ribeiro. Liderança: Um estudo sobre como o "bom ânimo" favorece a boa liderança. Revista Científica Multidisciplinar Núcleo do Conhecimento. Ano 05, Ed. 10, Vol. 11, pp. 38-48. Outubro de 2020. ISSN: 24480959, Link de acesso: https://www.nucleodoconhecimento.com.br/administracao/bom-animo

\section{RESUMO}

O presente ensaio teórico pretende investigar a postura psicológica e emocional por detrás da boa liderança. Através de observações da pesquisadora encontradas na literatura especializada em liderança, a isso somou-se a análise de pertinentes passagens do cânon cristão a fim de desvendar de que forma e se o bom ânimo e a motivação podem tornar o exercício da liderança bem sucedido.

Palavras-Chave: Liderança, motivação, administração, comportamento.

\section{INTRODUÇÃO}

Chiavenato (2000) nos ensina que a liderança é a influência interpessoal que é manifesta em uma determinada situação e dirigida por meios da comunicação humana para a consecução de um determinado objetivo. Sabemos que diversos objetivos organizacionais se estendem pelos médio e longo prazos, tornando assim os líderes imersos em muitos desafios e consequente cansaço emocional, psicológica e laboral. Os desafios de conduzir pessoas são dignos de nota, tanto para as organizações do primeiro, quanto das do segundo e terceiro setor. Assim, o presente ensaio tem como

\footnotetext{
${ }^{1}$ Pós-graduanda em Direito administrativo e Bacharel em Administração.
} 
foco inspirar os diversos líderes nas mais variadas camadas da sociedade para que desenvolvam em si a postura adequada para manterem suas lideranças de maneira saudável para si, para seus pares, para os stakeholders, bem como para a organização que tal líder representa.

Não se pode afirmar que haja um modelo de liderança único e infalível, que sirva como uma panaceia para todo e qualquer problema ou para qualquer empresa ou instituição.

Assim, a liderança é bem exercida à medida que o líder consegue identificar qual estilo de liderança a situação e seus liderados necessitam. De acordo com Maximiano (2000), estilo de liderança é a forma como o líder se interage com a equipe, seja em interações grupais ou individuais. A liderança pode ser autocrática, democrática ou liberal, dependendo de o líder centralizar ou compartilhar a autoridade com sua equipe. Dessa forma, é adequado destacar o fato de que a boa liderança é aquela que se adequa à situação, às pessoas, ao objetivo e ao cenário que se está inserida. De qualquer maneira, este não é o foco do presente ensaio, no entanto esta observação precisava ser apresentada: a liderança é emocional. De acordo com Diamond (2010), quanto mais importante a negociação, mais emocional a pessoal se torna - seja ele um acordo diplomático, um acordo bilionário, ou quando seus filhos querem um sorvete. Preste atenção: O mundo não é racional.

\section{TER BOM ÂNIMO x MOTIVAÇÃO}

Pode-se definir o conceito de "bom ânimo" como sinônimo de "motivação". O termo motivação ${ }^{1}$ origina do latim motus (movido) e motio (movimento). Já a palavra ânimo ${ }^{2}$ deriva do latim animus, que significa alma, coragem ou mente. O dicionário analógico da Língua Portuguesa ${ }^{3}$ define diversas analogias para o termo ânimo sendo alguns deles enérgico, caloroso, vivo, brilhante, empolgante, atrevido, arrojado, conceituoso, grave, de pulso, de força, elevado, grandioso, altivo, nobre, eloquente, ágil e apaixonado e como análogo à "motivação" o dicionário sugere a interjeição "ânimo!"4 . São esses termos mesmo bem semelhantes à definição de Chiavenato as características do empreendedor: 
Na verdade, o empreendedor é a pessoa que consegue fazer as coisas acontecerem, pois é dotado de sensibilidade para os negócios, tino financeiro e capacidade de identificar oportunidades. Com esse arsenal, transforma ideias em realidade, para benefício próprio e para benefício da comunidade. Por ter criatividade e um alto nível de energia, o empreendedor demonstra imaginação e perseverança, aspectos que, combinados adequadamente, o habilitam a transformar uma ideia simples e mal estruturada em algo concreto e bem-sucedido no mercado. (CHIAVENATO, 2007, p. 8 - grifo nosso)

Dessa forma, podemos e devemos ter associados termos como líder, empreendedor, gestor à termos como motivação e bom ânimo quando o que se almeja é sucesso nos empreendimentos. Maximiano, diz que:

A liderança é uma função, papel, tarefa ou responsabilidade que qualquer pessoa exerce, quando é responsável pelo desempenho de um grupo. Os líderes são essenciais para o desempenho, crescimento e gerenciamento de equipes dentro de uma organização. (MAXIMIANO, 2000, p. 33).

Assim, o presente ensaio teórico investiga a emoção que torna o sucesso possível. Que tipo de postura emocional o líder deve adotar a fim de viabilizar suas metas no médio e longo prazo? Existem posturas adotadas pelo líder que favoreçam o sucesso organizacional? Quais são elas? Independentemente do estilo de liderança ou perfil decisório que o indivíduo opte por adotar, ou que a situação o impila a exercer, quais são as atitudes que se busca em uma pessoa para a considerar bom líder?

Como outrora exposto, o presente estudo não busca desvendar quais são os estilos de liderança, mas qual é o estado emocional do líder que o torna melhor enquanto liderança. Para além dessa observação, a presente análise procura revelar quais são as atitudes mentais e emocionais que estruturam o bem estar e o sucesso do empreendedor, gestor, administrador, proprietário, presidente ou aquele que ocupa a posição de líder nas mais variadas áreas de nossa sociedade.

Motivação se define como um processo de intensidade, direção e persistência dos esforços de uma pessoa para o alcance de uma determinada meta. Embora a motivação, de uma maneira geral, se relacione ao esforço para atingir qualquer objetivo. (ROBBINS, 2008, p.132) 


\section{BOM ÂNIMO NA BÍBLIA}

Os líderes sempre exerceram um papel emocional primordial. Não há dúvida de que os primeiros líderes da humanidade - fossem chefes de clã ou líderes espirituais - conquistaram seu lugar em grande parte porque sua liderança era emocionalmente irresistível. Ao longo da história e em todas as culturas, o líder de qualquer grupo tem sido aquele para quem os outros se voltam em busca de segurança e clareza diante de uma incerteza ou de uma ameaça, ou quando há um trabalho a ser feito. O líder age como guia emocional do grupo. (GOLEMAN, 2002, p. 19)

Deste ponto em diante, o leitor poderia, precipitadamente, concluir que este ensaio teórico trata de uma visão religiosa da liderança. Outrossim, trata-se de uma investigação de sociologia e antropologia aplicadas à administração e à gerência de negócios.

Com outras palavras Burkett (1999) diz que honestidade, ética e valores morais são conceitos empresariais antigos. E aponta um interessante fato: nos Estados Unidos, a Bíblia é tida como livro de negócios há muitos séculos. Assim, um dos livros mais influentes e balizadores de nosso pensamento/comportamento social contemporâneo é a Bíblia. O cânon cristão é citado no presente ensaio não apenas por sua relevância histórica tão pouco por sua influência filosófica/espiritual, outrossim por suas orientações para os líderes. Estudando com atenção algumas passagens bíblicas podemos encontrar relatos de gestão e liderança. Neste ensaio estão compilados alguns dos casos em que o Deus dos cristãos recomenda que "se tenha bom ânimo" para aqueles que almejam sucesso em suas empreitadas. Assim, de encontro aos relatos de nossos entrevistados, a Bíblia também vem há milênios apontando que é do interior do ser humano que emerge a postura adequada, a decisão e atitude para a boa liderança.

Abaixo o leitor poderá acompanhar as referidas passagens dos escritos cristãos em que se aconselha que se "tenha bom ânimo":

JOSUÉ, 1:6-7

I CRÔNICAS, 28:20 
ESDRAS 10:4

DANIEL 10:19

JOÃO 16:33

ATOS 23:11

ATOS 27:22-25

Como citado anteriormente, o intuito deste ensaio não é o de pesquisa no campo da espiritualidade, o objetivo é o de pesquisar as emoções do bom líder. Assim, não se faz necessária a análise dos significados das passagens, porém muito relevante é ter o mínimo conhecimento a respeito de quem eram os personagens e de que tipo de liderança estava sendo tratada a passagem.

Para o Deus Bíblico não basta ordenar que se haja em acordo com o que a situação pede. Assim, pode-se verificar nas passagens abaixo detalhadas que para além de se buscar ser um bom gestor no contexto em que se atua, um determinado tipo de atitude deveria vir acompanhado: "tende bom ânimo". Em tais passagens os personagens foram aconselhados a se ter bom ânimo, força e coragem na execução de suas obrigações

cotidianas.

Assim, abaixo encontram-se as passagens e uma breve contextualização sobre quem era o líder envolvido na cena citada:

\subsection{JOSUÉ}

Esforça-te, e tem bom ânimo, porque tu farás a este povo herdar a terra que jurei a seus pais Ihes daria. Tão-somente esforça-te e tem mui bom ânimo, cuidado de fazer conforme a toda a lei que meu servo Moisés te ordenou; dela não te desvies, nem para a direita nem para a esquerda, a fim de que sejas bem sucedido por onde quer que andares. A Bíblia (JOSUÉ, 1:6-7)

\section{Contexto histórico:}

Deus fala com o líder dos hebreus, Josué, após a morte de seu antecessor, Moisés. Josué herdou a desafiadora missão de coordenar, conduzir e liderar centenas de 
milhares de pessoas em uma épica jornada do Egito rumo à terra prometida por Deus. Diante de todos os problemas típicos de um deserto e dos mais variados problemas nos relacionamentos interpessoais de seus liderados a recomendação: "tende bom ânimo".

\subsection{CRÔNICAS}

E disse Davi a seu filho Salomão: Esforça-te e tem bom ânimo, e faze a obra; não temas, nem te desalentes; pois o Senhor Deus, meu Deus, é contigo; não te deixará, nem te desamparará, até que seja acabada toda a obra para o serviço da casa do Senhor. A Bíblia (I CRÔNICAS, 28:20)

\section{Contexto histórico:}

Salomão é considerado um dos mais ricos homens da história e um dos mais inteligentes. Diante do início de sua jornada como rei de Israel, seu pai, o renomado rei Davi, aconselha o autor do livro de Provérbios e Eclesiastes: "tende bom ânimo".

\subsection{ESDRAS}

Levanta-te; pois a ti pertence este negócio, e nós somos contigo; tem bom ânimo e faze-o. A Bíblia (ESDRAS 10:4)

\section{Contexto histórico:}

Esta é uma passagem muito inusitada, em que a cena se inverte e o povo aconselha o sacerdote. Depois do cativeiro do povo hebreu na Babilônia, Esdras, sacerdote e mestre da lei, estava envolvido no contexto da turbulenta e confusa reconstrução do templo em Jerusalém. Após a decisão do rei Ciro por permitir e contribuir para a reconstrução do templo, Esdras se encarrega de verificar se o povo israelita está cumprindo os mandamentos de Deus. Ao se deparar com o descumprimento das leis de Deus Esdras se entristece profundamente com seu povo. Neste momento de profunda reflexão e choro, Secanias (homem citado apenas em relatos de árvores genealógicas) se aproxima de Esdras e aconselha o sacerdote para que se reerga, reassuma o papel de sacerdote e com bom ânimo retome o seu propósito em conduzir aquelas pessoas para mais próximo da lei do Deus hebreu. 


\subsection{DANIEL}

E disse: Não temas, homem muito amado; paz seja contigo; sê forte, e tem bom ânimo. E quando ele falou comigo, fiquei fortalecido, e disse: fala, meu senhor, pois me fortaleceste. A Bíblia (DANIEL 10 :19)

\section{Contexto histórico:}

Daniel foi um grande profeta do Antigo Testamento. Prisioneiro de guerra pelas tropas do Império Babilônico, Daniel se livrou de diversos problemas, castigos e até da morte graças a sua capacidade de interpretar sonhos. Na referida passagem um ser celestial o encontra após um período de muito sofrimento, após Daniel ter previsto um período de grande guerra, pelo qual chora intensamente e se priva de prazeres alimentares por três semanas. No relato bíblico acima mencionado, Daniel ao receber o anjo inicialmente se assusta e por fim é por este acalmado e acalentado com palavras de bom ânimo.

\subsection{JOÃO}

Tenho-vos dito estas coisas, para que em mim tenhais paz. No mundo tereis tribulações; mas tende bom ânimo, eu venci o mundo. A Bíblia (JOÃO 16:33)

\section{Contexto histórico:}

Aqui é Jesus que fala. Durante a última ceia, Jesus lava os pés de seus discípulos e os aconselhar com diversas palavras a respeito de estar em comunhão com o Pai. Dizendo Jesus, em outras palavras, que aquele que buscar o Pai será protegido pelo Deus bíblico. Após falar sobre os sofrimentos do povo de Deus e relatar, por exemplo, sobre como este precisa ser aperfeiçoado enquanto ser humano, o que o diz também em João 15:2 através das seguintes palavras: "Toda a vara em mim, que não dá fruto, a tira; e limpa toda aquela que dá fruto, para que dê mais fruto." Ou seja, se fores uma pessoa que produz será podada para que cresça mais, e se fores uma pessoa sem frutos serás eliminado, para dar lugar para quem produz. Assim, prossegue Jesus com suas últimas recomendações para a humanidade alertando-nos de que em nossas vidas teremos diversos momentos turbulentos, mas que devemos ter bom ânimo. 


\subsection{ATOS}

Na noite seguinte, apresentou-se lhe o Senhor e disse: Tem bom ânimo: porque, como deste testemunho de mim em Jerusalém, assim importa que o dês também em Roma. A Bíblia (ATOS 23:11)

\section{Contexto histórico:}

Paulo, outrora Saulo, perseguidor de cristãos, se torna então um dos maiores nomes no cristianismo. Paulo pregou para milhares de pessoas e nos deixou suas palavras e passos registrados no Novo Testamento. Na referida passagem, o Deus da Bíblia exorta o líder Paulo para que tenhas bom ânimo para que prossiga em sua desafiadora jornada assim como já vinha fazendo com muito ardor.

\section{Outras palavras para "bom ânimo"}

Nas diversas traduções bíblicas podemos encontrar outros termos utilizados onde aqui se apresentou a palavra ânimo, são algumas delas:

\begin{tabular}{|c|c|c|}
\hline $\begin{array}{l}\text { Tradução } \quad \text { para } \\
\text { "ânimo": }\end{array}$ & Passagens: & Versão da tradução bíblica: \\
\hline Corajoso & JOSUÉ 1:7 & $\begin{array}{l}\text { Almeida Revista e Atualizada; Nova Versão } \\
\text { Internacional; Nova Versão Transformadora; } \\
\text { Versão Católica }\end{array}$ \\
\hline Forte & JOSUÉ $1: 7$ & Sociedade Bíblica Britânica; \\
\hline Corajoso & $\begin{array}{l}\text { I } \\
\text { CRÔNICAS } \\
\text { 28:20 }\end{array}$ & $\begin{array}{l}\text { Nova Versão Transformadora; Almeida } \\
\text { Atualizada; Nova Tradução na Linguagem } \\
\text { de Hoje; Nova Versão Internacional }\end{array}$ \\
\hline Coragem & $\begin{array}{l}\text { ESDRAS } \\
10: 4\end{array}$ & Nova Versão Internacional \\
\hline Forte & $\begin{array}{l}\text { ESDRAS } \\
10: 4\end{array}$ & $\begin{array}{l}\text { João Ferreira de Almeida Revista e } \\
\text { Atualizada }\end{array}$ \\
\hline Forte & $\begin{array}{l}\text { DANIEL } 10 \\
: 19\end{array}$ & $\begin{array}{l}\text { João Ferreira de Almeida Revista e } \\
\text { Atualizada; Nova Versão Internacional }\end{array}$ \\
\hline
\end{tabular}




\begin{tabular}{|l|l|l|}
\hline Coragem & JOÃO & Nova Tradução na Linguagem de Hoje \\
& $16: 33$ & \\
\hline Coragem & ATOS & Nova Tradução na Linguagem de Hoje; João \\
& $23: 11$ & Ferreira de Almeida Revista e Atualizada \\
\hline
\end{tabular}

Fonte: autor.

\section{CONSIDERAÇÕES FINAIS}

Por fim, não se pode afirmar que bastaria bom ânimo para ter sucesso nas empreitadas, mas pode-se dizer que bastaria o desânimo para que os planos comecem a ruir nos negócios que se empreende.

Ter bom ânimo é essencial para a boa liderança. O líder é uma espécie de guia para seus liderados. O estado de espírito do líder influencia e colabora para o clima organizacional. Assim, um líder com bom ânimo inspirará as pessoas a estarem mais motivadas, empenhadas e comprometidas com seus trabalhos.

Assim, de acordo com Maxwell (2008), de certa forma, parte da responsabilidade pelo desenvolvimento das pessoas recai sobre o líder. Isso está para além do que apenas ajudá-las a adquirir habilidades profissionais. Os melhores líderes ajudam a equipe não só em relação à carreira, mas também em relação à vida pessoal. Eles os ajudam a se tornar pessoas melhores, e não apenas bons profissionais. Os líderes potencializam os liderados. $\mathrm{E}$ isso é muito importante, pois promover o crescimento das pessoas gera crescimento para a organização.

\section{REFERÊNCIAS}

A BíBLIA. Tradução de João Ferreira Almeida. Velho Testamento e Novo Testamento. Rio de Janeiro: King Cross Publicações, 2008.

ALMEIDA, Fabio Py Murta. Uma introdução ao livro de Josué. Arquivo Maaravi: Revista Digital de Estudos Judaicos da UFMG, v. 4, n. 7, p. 27-34, 2010. 
BURKETT, L. Os negócios de acordo com a Bíblia. São Paulo: Madras, 1999.

CHIAVENATO, I. Introdução à Teoria Geral da Administração, $2^{\underline{a}}$ ed. Rio de Janeiro: Campus, 2000.

CHIAVENATO, Idalberto Empreendedorismo: dando asas ao espírito empreendedor, $2^{\underline{a}}$ ed. rev. e atualizada. São Paulo: Saraiva, 2007.

COSTA, I. Esdras - resenhas dos livros da Bíblia. 2018. Disponível em: https://www.youtube.com/watch?v=WiP8mlJOTR8. Acesso em 29/08/2020.

DIAMOND, S. Getting More: How You Can Negotiate to Succeed in Work and Life, $1^{\underline{a}}$ ed. NY: Currency, 2010.

FRAZÃO, Dilva. Salomão - Rei de Israel. 2019. Disponível em: https://www.ebiografia.com/salomao. Acesso em 27/08/2020.

GOLEMAN, Daniel; BOYATZIS, Richard; MCKEE, Annie. O poder da inteligência emocional. Rio de Janeiro: Campus, 2002.

MAXIMIANO, A.C.A. Teoria Geral da Administração: da escola científica à competitividade na economia globalizada, $2^{\mathrm{a}}$ ed. São Paulo: Atlas, 2000.

MAXIMIANO, Antonio Cesar Amaru. Introdução à Administração. $5^{a}$ ed. São Paulo: Atlas. 2000.

MAXWELL, John C. O livro de ouro da liderança. Rio de Janeiro: Thomas Nelson Brasil, 2008.

PEREIRA, Leonardo. O Livro De Josué. Clube de Autores (managed), 2019.

PEREIRA, Leonardo. Esdras-Um Homem Dedicado Na Lei De Deus. Clube de Autores (managed), 2019.

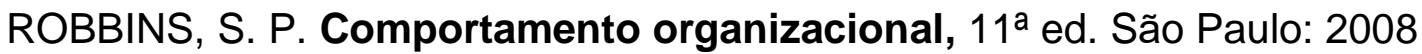


WHITCOMB, John C. Daniel: Comentário bíblico Portavoz. Editorial Portavoz, 2019.

\section{APÊNDICE - REFERÊNCIAS DE NOTA DE RODAPÉ}

1. Conceito de motivação - O que é, Definição e Significado. 2011. Disponível em: https://conceito.de/motivacao. Acesso em 11/09/2020.

2. Significado de Ânimo. 2016. Disponível em: https://www.significados.com.br/animo. Acesso em 11/09/2020.

3. AZEVEDO, Francisco Ferreira dos Santos. Dicionário Analógico da língua portuguesa: ideias afins/thesaurus. $2^{a}$ ed. atual e revista. Rio de Janeiro: Lexikon, 2010. Página 251

4. AZEVEDO, Francisco Ferreira dos Santos. Dicionário Analógico da língua portuguesa: ideias afins/thesaurus. $2^{\underline{a}}$ ed. atual e revista. Rio de Janeiro: Lexikon, 2010. Página 274

Enviado: Setembro, 2020.

Aprovado: Outubro, 2020. 